\title{
Retrogradation of Waxy Rice Starch Gel in the Vicinity of the Glass Transition Temperature
}

\author{
Sanguansri Charoenrein and Sunsanee Udomrati \\ Department of Food Science and Technology, Faculty of Agro-Industry, Kasetsart University, Bangkok 10900, Thailand \\ Correspondence should be addressed to Sanguansri Charoenrein; fagisscr@ku.ac.th
}

Received 26 February 2013; Revised 11 May 2013; Accepted 20 May 2013

Academic Editor: Fernanda Fonseca

Copyright (C) 2013 S. Charoenrein and S. Udomrati. This is an open access article distributed under the Creative Commons Attribution License, which permits unrestricted use, distribution, and reproduction in any medium, provided the original work is properly cited.

\begin{abstract}
The retrogradation rate of waxy rice starch gel was investigated during storage at temperatures in the vicinity of the glass transition temperature of a maximally concentrated system $\left(T_{g}^{\prime}\right)$, as it was hypothesized that such temperatures might cause different effects on retrogradation. The $T_{g}^{\prime}$ value of fully gelatinized waxy rice starch gel with $50 \%$ water content and the enthalpy of melting retrograded amylopectin in the gels were investigated using differential scanning calorimetry. Starch gels were frozen to $-30^{\circ} \mathrm{C}$ and stored at $4,0,-3,-5$, and $-8^{\circ} \mathrm{C}$ for 5 days. The results indicated that the $T_{g}^{\prime}$ value of gelatinized starch gel annealed at $-7^{\circ} \mathrm{C}$ for $15 \mathrm{~min}$ was $-3.5^{\circ} \mathrm{C}$. Waxy rice starch gels retrograded significantly when stored at $4^{\circ} \mathrm{C}$ with a decrease in the enthalpy of melting retrograded starch in samples stored for 5 days at $-3,-5$, and $-8^{\circ} \mathrm{C}$, respectively, perhaps due to the more rigid glass matrix and less molecular mobility facilitating starch chain recrystallization at temperatures below $T_{g}^{\prime}$. This suggests that retardation of retrogradation of waxy rice starch gel can be achieved at temperature below $T_{g}^{\prime}$.
\end{abstract}

\section{Introduction}

The retrogradation of starch has been defined as a process which occurs when the molecules comprising gelatinized starch begin to reassociate in an ordered structure [1]. Retrogradation can lead to an obvious increase in the firmness of stored baked goods [2] and frozen cooked rice [3], making them unattractive to consumers. However, in some products, retrogradation can provide a desirable quality such as in the manufacture of rice stick noodles [4], resistant starch type 3 [5] croutons, and bread crumb [6]. For this reason, numerous studies have been performed to examine the factors affecting the retrogradation of starch. Water content and storage temperatures play key roles in the extent of retrogradation. The maximum extent of retrogradation of most starches is attained in starch gels containing $50 \%-60 \%$ solids [7-10]. It was also found that starch gels retrograde faster when stored at $4-6^{\circ} \mathrm{C}[11,12]$.

Glass transition is a second-order phase transition that occurs over the temperature range at which amorphous solid materials (glassy materials) are transformed to a metastable leathery state [13]. A special glass transition temperature, denoted as $T_{g}^{\prime}$, has been defined as the glass transition of a maximally freeze-concentrated system [14]. $T_{g}^{\prime}$ plays a key role in the quality and storage stability of frozen products because the rate of deteriorative changes in frozen food is closely related to $T_{g}^{\prime}[13,15]$. Below $T_{g}^{\prime}$, where the food matrix is in a glassy state, molecular mobility decreases and consequently reduces the rate of deteriorative changes involving molecular mobility. Due to the fact that retrogradation of gelatinized starch involves the movement and rearrangement of starch chains to form a junction zone [16], we hypothesized that the extent of retrogradation process of starch gels at temperatures below and above $T_{g}^{\prime}$ should be different. Although there have been some studies on the influence of storage temperatures on the extent of retrogradation, these studies used ambient temperature, refrigeration $\left(4\right.$ or $\left.5^{\circ} \mathrm{C}\right)$, and frozen storage $\left(-20^{\circ} \mathrm{C}\right)[11,17]$ but not temperatures in the vicinity of $T_{g}^{\prime}$. Moreover, all of these experiments used samples which were gelatinized in differential scanning calorimeter (DSC) pans. This static gelatinization might not 
mimic the real heating process of starch suspension which usually includes stirring the suspension during application of heat. Heating with shear would completely paste the starch suspension while heating without shear might cause incomplete pasting. Moreover previous studies [10] have shown that maximum retrogradation occurred in rice starch gels with $40 \%-60 \%$ water content. In this paper, we present an alternative method to prepare completely gelatinized starch gels and then limit the water content to $50 \%$ to provide maximum retrogradation. This research will make a contribution toward an improvement in the acceleration or retardation of retrogradation of starch-based products.

\section{Materials and Methods}

2.1. Materials. Waxy rice starch was made from Thai waxy rice grains ( $\mathrm{RD} 6$ ), grown in the Kalasin province area and aged at least six months.

2.2. Flour and Starch Preparation. Rice kernels were soaked in water for $4 \mathrm{~h}$ and then ground with water using a doubledisc stone mill. The slurry was centrifuged for $15 \mathrm{~min}$ and dried at $45^{\circ} \mathrm{C}$ for $15 \mathrm{~h}$. The flour was ground in a hammer mill and passed through a 100-mesh sieve; then it was stored at room temperature in sealed plastic bags. For the isolation of waxy rice starch from waxy rice flour, the method of Hogan [18] was used. Waxy rice flour was mixed with sodium hydroxide solution. The slurry was stirred, filtered, and centrifuged. The sediment was washed with water, neutralized with hydrochloric acid solution, and dried. The rice starch was then ground in a hammer mill and passed through a 100mesh sieve. The granule size of was $2.8-5.1 \mu \mathrm{m}$ with mean diameter of $3.8 \pm 0.7 \mu \mathrm{m}$. The protein, fat, and ash contents of waxy rice starch were $0.20 \pm 0.00,0.05 \pm 0.00$, and $0.03 \pm$ $0.00 \mathrm{~g} / 100 \mathrm{~g}$ dried solid by the AACC Method 46-12, 30-25, and $08-01$, respectively [19]. The moisture content was $11.07 \pm$ $0.10 \mathrm{~g} / 100 \mathrm{~g}$ by the AACC Method 44-15A [19]. The amylose content of waxy rice starch was $6.49 \pm 0.13 \mathrm{~g} / 100 \mathrm{~g}$ dried solid by the method of Juliano [20].

2.3. Waxy Rice Starch Gel Preparation. A starch suspension $(10 \% \mathrm{w} / \mathrm{w})$ was prepared by mixing the waxy rice starch in distilled water and stirring continuously at $250 \mathrm{rpm}$ for $1 \mathrm{~h}$ followed by $200 \mathrm{rpm}$ at $95^{\circ} \mathrm{C}$ for $1 \mathrm{~h}$. The gelatinized starch sample was then put in stainless steel DSC pans. Water in each sample was allowed to evaporate at room temperature until the final water content was $50 \%$ as determined by weighing. The final sample weight in each pan was $20-30 \mathrm{mg}$. The pans were hermetically sealed to prevent moisture loss. The sealed pans were separated into two sets with one set being used for glass transition determination and the other set being used in the retrogradation study.

2.4. Glass Transition Temperature $\left(T_{g}^{\prime}\right)$ Determination. A Pyris-1 DSC (Perkin Elmer, Norwalk, CT, USA) equipped with an intracooler subambient accessory was used. Nitrogen gas was used as the purge gas at a flow rate of $20 \mathrm{~mL} / \mathrm{min}$ during calibration and measurements. The instrument was calibrated using indium and ice. An empty pan was used as a reference sample. Each sample in a sealed DSC pan was cooled to $-60^{\circ} \mathrm{C}$ and then heated to $25^{\circ} \mathrm{C}$ at $5^{\circ} \mathrm{C} / \mathrm{min}$ to determine the glass transition temperature of a nonannealed state. For the isothermal annealing treatment, the samples were cooled to $-60^{\circ} \mathrm{C}$ and held for $15 \mathrm{~min}$, heated to three different annealing temperatures $\left(-4,-7\right.$, and $\left.-10^{\circ} \mathrm{C}\right)$ in the vicinity of the $T_{g}^{\prime}$ of a nonannealed sample and held at this temperature for $15 \mathrm{~min}$, and cooled back to $-60^{\circ} \mathrm{C}$ at $10^{\circ} \mathrm{C} / \mathrm{min}$ and reheated to $25^{\circ} \mathrm{C}$ at $5^{\circ} \mathrm{C} / \mathrm{min}$ to locate the $T_{g}^{\prime}$. The $T_{g}^{\prime}$ was indicated by an onset temperature of the heat capacity change, which was determined using the computer software program associated with the Perkin Elmer instrument. All measurements were run in triplicates.

2.5. Amylopectin Retrogradation Analysis. The sealed DSC pans with gelatinized starch were frozen to $-30^{\circ} \mathrm{C}$ in a cooling bath and held for $1 \mathrm{~h}$ and then immediately stored at -8 , $-5,-3,0$, and $4^{\circ} \mathrm{C}$ for 5 days. Storage at $-8,-5$, and $-3^{\circ} \mathrm{C}$ was done in a cooling bath while the samples at 0 and $4^{\circ} \mathrm{C}$ were kept in a low temperature incubator (Model IPP 400, Memmert, Germany). After storage, the pans were left to stand for $30 \mathrm{~min}$ at room temperature to equilibrate and then heated from 25 to $120^{\circ} \mathrm{C}$ in the $\mathrm{DSC}$ at $10^{\circ} \mathrm{C} / \mathrm{min}$ to observe the melting peak of the retrograded starch gels. All measurements were performed in triplicate.

\section{Results and Discussion}

3.1. Glass Transition. In a system that is allowed to form the maximum amount of ice, the glass transition of this maximally freeze-concentrated matrix occurs at $T_{g}^{\prime}$ and is independent of the initial solids fraction (before freezing) [21]. However, if the maximum amount of ice is not formed in the system, the resulting unfrozen matrix will be more dilute. Annealing is a way to form a maximally freeze-concentrated phase. The DSC thermograms showing the $T_{g}^{\prime}$ values of the gelatinized waxy rice starch isothermally annealed at different temperatures are presented in Figure 1. The $T_{g}^{\prime}$ value of the gelatinized waxy rice starch was about $-5^{\circ} \mathrm{C}$ in the nonannealed state. At the three different annealing temperatures of $-4,-7$, and $-10^{\circ} \mathrm{C}$, the $T_{g}^{\prime}$ value of gelatinized waxy rice starch was $-4,-3.5$, and $-4.2^{\circ} \mathrm{C}$, respectively. The annealing temperature of $-7^{\circ} \mathrm{C}$ resulted in the highest $T_{g}^{\prime}$ value and the most clearly detectable among the three annealing temperatures. This might have occurred because this temperature, which was slightly below the $T_{g}^{\prime}$ of the gelatinized waxy rice starch $\left(-5^{\circ} \mathrm{C}\right)$, was high enough to have sufficient molecular mobility for ice formation and yet also low enough to maintain the amorphous glass matrix as discussed by Lim et al. [22]. Our $T_{g}^{\prime}$ result of $-3.5^{\circ} \mathrm{C}$ agreed relatively well with Slade and Levine [23], Roos and Karel [24], and Israkarn and Charoenrein [25] who found that the $T_{g}^{\prime}$ values of gelatinized wheat starch, gelatinized waxy corn starch, and cooked rice stick noodles were $-5,-6$, and $-4^{\circ} \mathrm{C}$, respectively. 


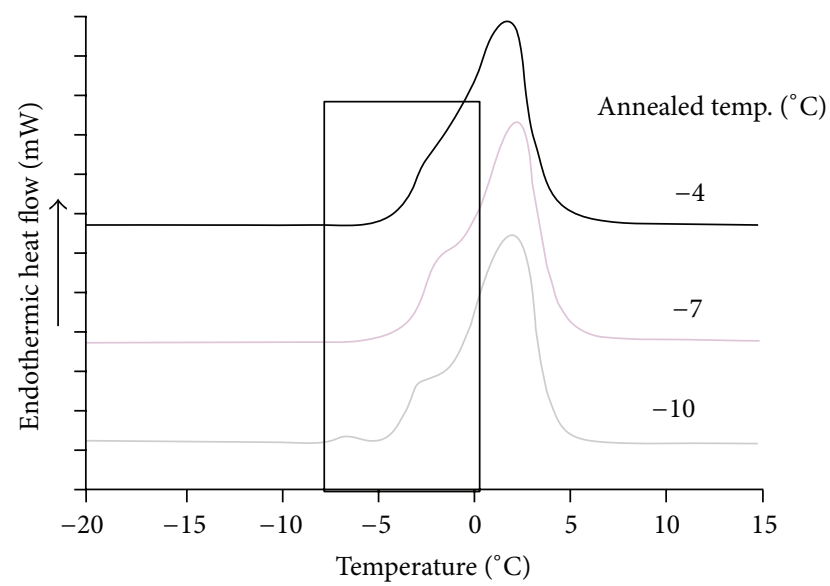

FIGURE 1: Differential scanning calorimetry thermograms showing glass transition temperature $\left(T_{g}^{\prime}\right)$ of waxy rice starch gel samples which were isothermally annealed at $-4,-7$, and $-10^{\circ} \mathrm{C}$ for $15 \mathrm{~min}$.

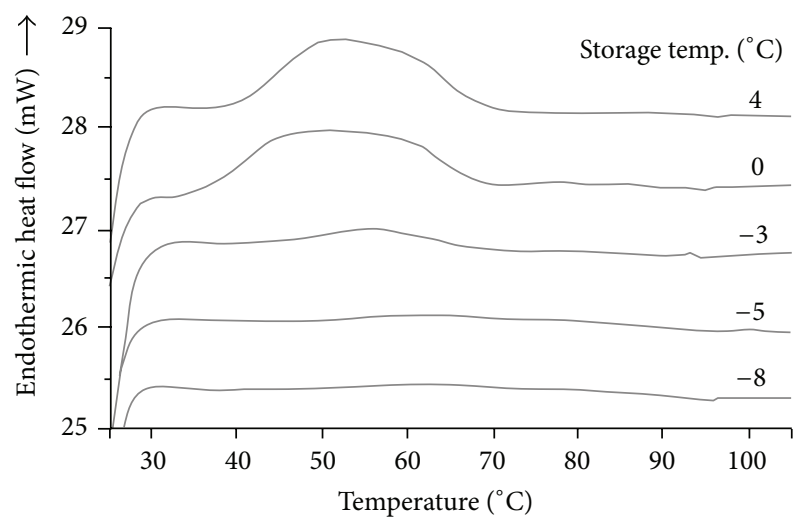

FIGURE 2: Differential scanning calorimetry melting endotherms obtained from waxy rice starch gel samples containing $50 \%$ water content stored at $4,0,-3,-5$, and $-8^{\circ} \mathrm{C}$ for 5 days.

3.2. Amylopectin Retrogradation. In this study, waxy rice starch was selected because it showed a well-defined melting peak of retrograded amylopectin at temperature range of $40-75^{\circ} \mathrm{C}$. The method of gel preparation used in this study included (1) shearing during heating, which provided a fully gelatinized starch sample, and (2) control of the water content at $50 \%$ to obtain the maximum retrogradation extent. Gelatinized waxy rice starch samples stored at various temperatures in the vicinity of the $T_{g}^{\prime}$ for 5 days showed differences in enthalpy of melting of the retrograded starch gels (Figures 2 and 3 ). The peak of melting of retrograded starch was large in samples stored at 4 and $0^{\circ} \mathrm{C}$. Samples stored at $-3^{\circ} \mathrm{C}$ showed a small peak while a very small peak and no peak were shown in samples stored at -5 and $-8^{\circ} \mathrm{C}$, respectively, which were temperatures below $T_{g}^{\prime}\left(\right.$ at $\left.-3.5^{\circ} \mathrm{C}\right)$. This indicated that at temperature below the glass transition temperature, the movement of starch chains to form junction zone of retrogradation was hindered. The results also agreed with Baik et al. [26] who reported that waxy rice starch gels stored at subzero temperature $\left(-12^{\circ} \mathrm{C}\right)$ showed a lower

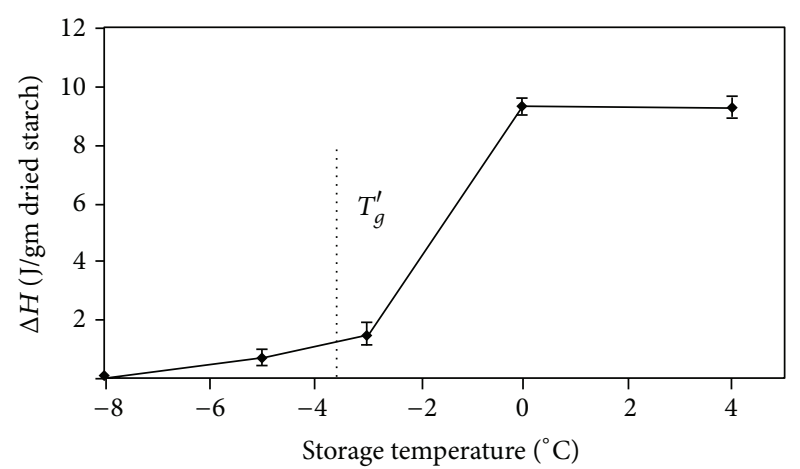

Figure 3: Enthalpy of melting retrograded waxy rice starch gel samples containing $50 \%$ water content as a function of storage temperature after 5-day storage.

degree of recrystallization of starch than those stored at $4^{\circ} \mathrm{C}$. However, their intervals of storage temperature were greater than those in our studies.

\section{Conclusions}

The onset of $T_{g}^{\prime}$ of the gelatinized waxy rice starch gel annealed at $-7^{\circ} \mathrm{C}$ for $15 \mathrm{~min}$ was $-3.5^{\circ} \mathrm{C}$. The results showed that rice starch gels retrograded substantially when stored at $4^{\circ} \mathrm{C}$ for 5 days. Decreases in the enthalpy of melting of retrograded starch gel were observed in samples stored at -3 , -5 , and $-8^{\circ} \mathrm{C}$. This was due to the more rigid glass matrix and less molecular mobility at temperatures below $T_{g}^{\prime}$. These results suggested that the retardation of retrogradation of waxy rice starch gel can be manipulated by a temperature below $T_{g}^{\prime}$ and acceleration could be carried out at temperature above $T_{g}^{\prime}$.

\section{References}

[1] W. A. Atwell, L. F. Hood, E. Varriano-Marston, and H. F. Zobel, "The terminology and methodology associated with basic starch phenomena," Cereal Foods World, vol. 33, pp. 306311, 1988.

[2] N. Sozer, R. Bruins, C. Dietzel, W. Franke, and J. L. Kokini, "Improvement of shelf life stability of cakes," Journal of Food Quality, vol. 34, no. 3, pp. 151-162, 2011.

[3] S. Yu, Y. Ma, and D.-W. Sun, "Effects of freezing rates on starch retrogradation and textural properties of cooked rice during storage," LWT-Food Science and Technology, vol. 43, no. 7, pp. 1138-1143, 2010.

[4] P. Satmalee and S. Charoenrein, "Acceleration of ageing in rice stick noodle sheets using low temperature," International Journal of Food Science and Technology, vol. 44, no. 7, pp. 13671372, 2009.

[5] R. C. Eerlingen, H. Jacobs, and J. A. Delcour, "Enzyme-resistant starch. 5: effect of retrogradation of waxy maize starch on enzyme susceptibility," Cereal Chemistry, vol. 71, pp. 351-355, 1994.

[6] M.-A. Ottenhof and I. A. Farhat, "Starch retrogradation," Biotechnology and Genetic Engineering Reviews, vol. 21, pp. 215228, 2004. 
[7] J. K. Zeleznak and R. C. Hoseney, "The role of water in the retrogradation of wheat starch gels and bread crumb," Cereal Chemistry, vol. 63, pp. 407-411, 1986.

[8] L. Slade and H. Levine, "Recent advances in starch retrogradation," in Recent Development in Industrial Polysaccharides, S. S. Stivala, V. Crescenzi, and M. C. I. Dea, Eds., pp. 387-430, 1987.

[9] Q. Liu and D. B. Thompson, "Effects of moisture content and different gelatinization heating temperatures on retrogradation of waxy-type maize starches," Carbohydrate Research, vol. 314, no. 3-4, pp. 221-235, 1998.

[10] S. Charoenrein and S. Udomrati, "The role of water in the retrogradation of rice starch gels," in Starch: From Polysaccharides To Granules, Simple and Mixture Gels, V. P. Yuryev, P. Tomasik, and H. Ruck, Eds., pp. 195-201, 2004.

[11] J. K. Zeleznek and R. C. Hoseney, "Characterization of starch from bread aged at different temperature," Starch/Stärke, vol. 39, pp. 231-233, 1987.

[12] R. D. L. Marsh and J. M. V. Blanshard, "The application of polymer crystal growth theory to the kinetics of formation of the B-amylose polymorph in a 50\% wheat-starch gel," Carbohydrate Polymers, vol. 9, no. 4, pp. 301-317, 1988.

[13] Y. H. Roos, Phase Transitions in Foods, Academic Press, San Diego, Calif, USA, 1995.

[14] H. Levine and L. Slade, "Principles of cryostabilization technology from structure/property relationships of carbohydrate/water systems: a review," Cryo-Letters, vol. 9, pp. 21-63, 1988.

[15] B. Bhandari and T. Howes, "Glass transition in processing and stability of food," Food Australia, vol. 52, no. 12, pp. 579-585, 2000.

[16] V. J. Morris, "Starch gelation and retrogradation," Trends in Food Science and Technology, vol. 1, pp. 2-6, 1990.

[17] Y. J. Wang and J. Jane, "Correlation between glass transition temperature and starch retrogradation in the presence of sugars and maltodextrins," Cereal Chemistry, vol. 71, pp. 527-531, 1994.

[18] T. J. Hogan, "The manufacture of rice starch," in Starch: Chemistry and Technology, L. R. Whistler and F. E. Paschall FE, Eds., vol. 2, pp. 65-76, Academic Press, New York, NY, USA, 1967.

[19] AACC, Approved Methods of the American Association of Cereal Chemists, The American Association of Cereal Chemists, Inc., 10th edition, 2000.

[20] O. B. Juliano, "A simplified assay for milled-rice amylose," Cereal Science Today, vol. 6, pp. 335-337, 1971.

[21] M. P. Buera, Y. Roos, H. Levine et al., "State diagrams for improving processing and storage of foods, biological materials, and pharmaceuticals (IUPAC Technical Report)," Pure and Applied Chemistry, vol. 83, no. 8, pp. 1567-1617, 2011.

[22] M. H. Lim, H. Wu, and D. S. Reid, "The effect of starch gelatinization and solute concentrations on $T_{g}^{\prime}$ of starch model system," Journal of the Science of Food and Agriculture, vol. 80, pp. 1757-1762, 2000.

[23] L. Slade and H. Levine, "Non-equilibrium melting of native granular starch. Part I. Temperature location of the glass transition associated with gelatinization of A-type cereal starches," Carbohydrate Polymers, vol. 8, no. 3, pp. 183-208, 1988.

[24] Y. H. Roos and M. Karel, "Water and molecular weight effects on glass transitions in amorphous carbohydrates and carbohydrate solutions," Journal of Food Science, vol. 56, pp. 1676-1681, 1991.
[25] K. Israkarn and S. Charoenrein, "Influence of annealing temperature on $T_{g}^{\prime}$ of cooked rice stick noodles," International Journal of Food Properties, vol. 9, no. 4, pp. 759-766, 2006.

[26] M.-Y. Baik, K.-J. Kim, K.-C. Cheon, Y.-C. Ha, and W.-S. Kim, "Recrystallization kinetics and glass transition of rice starch gel system," Journal of Agricultural and Food Chemistry, vol. 45, no. 11, pp. 4242-4248, 1997. 

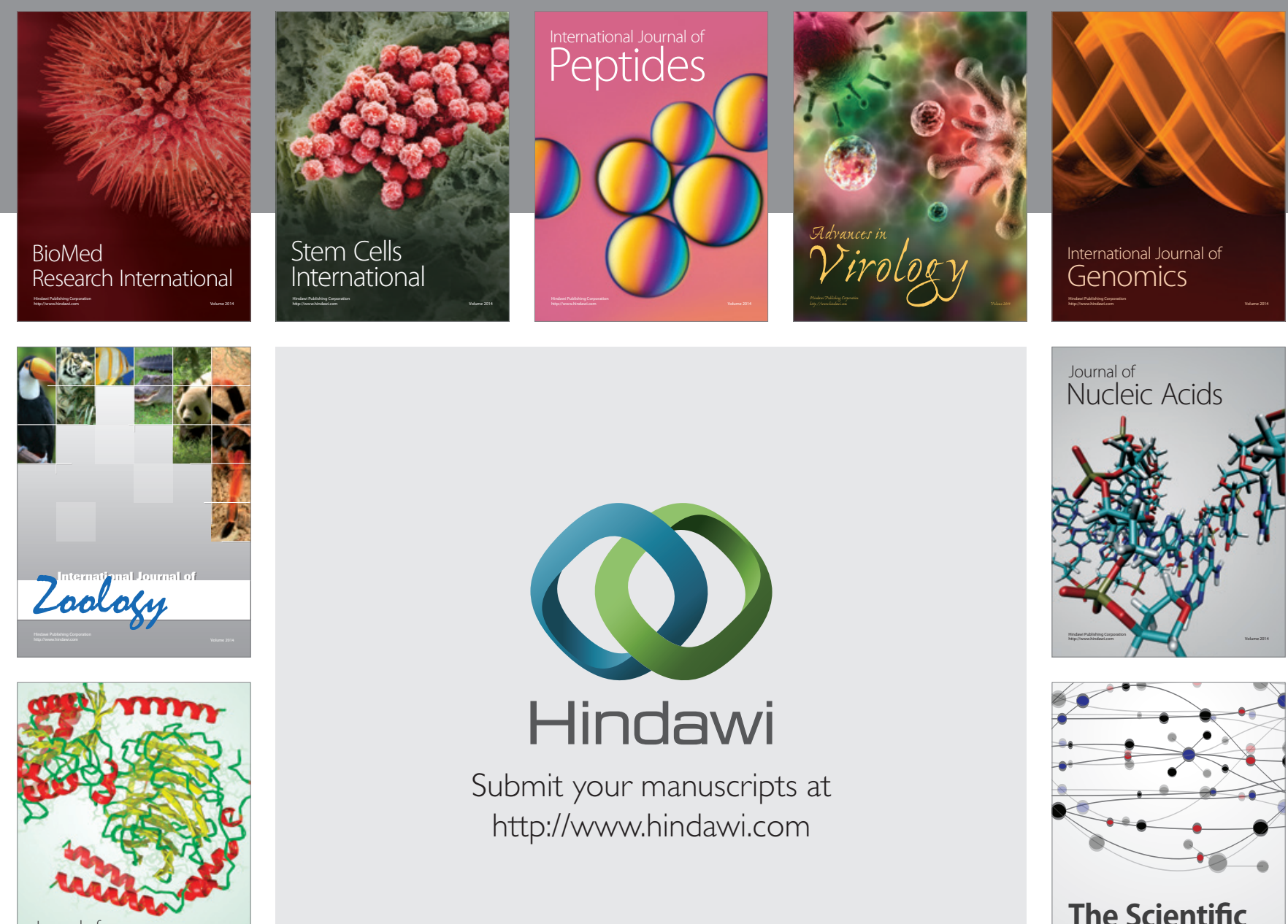

Submit your manuscripts at

http://www.hindawi.com

Journal of
Signal Transduction
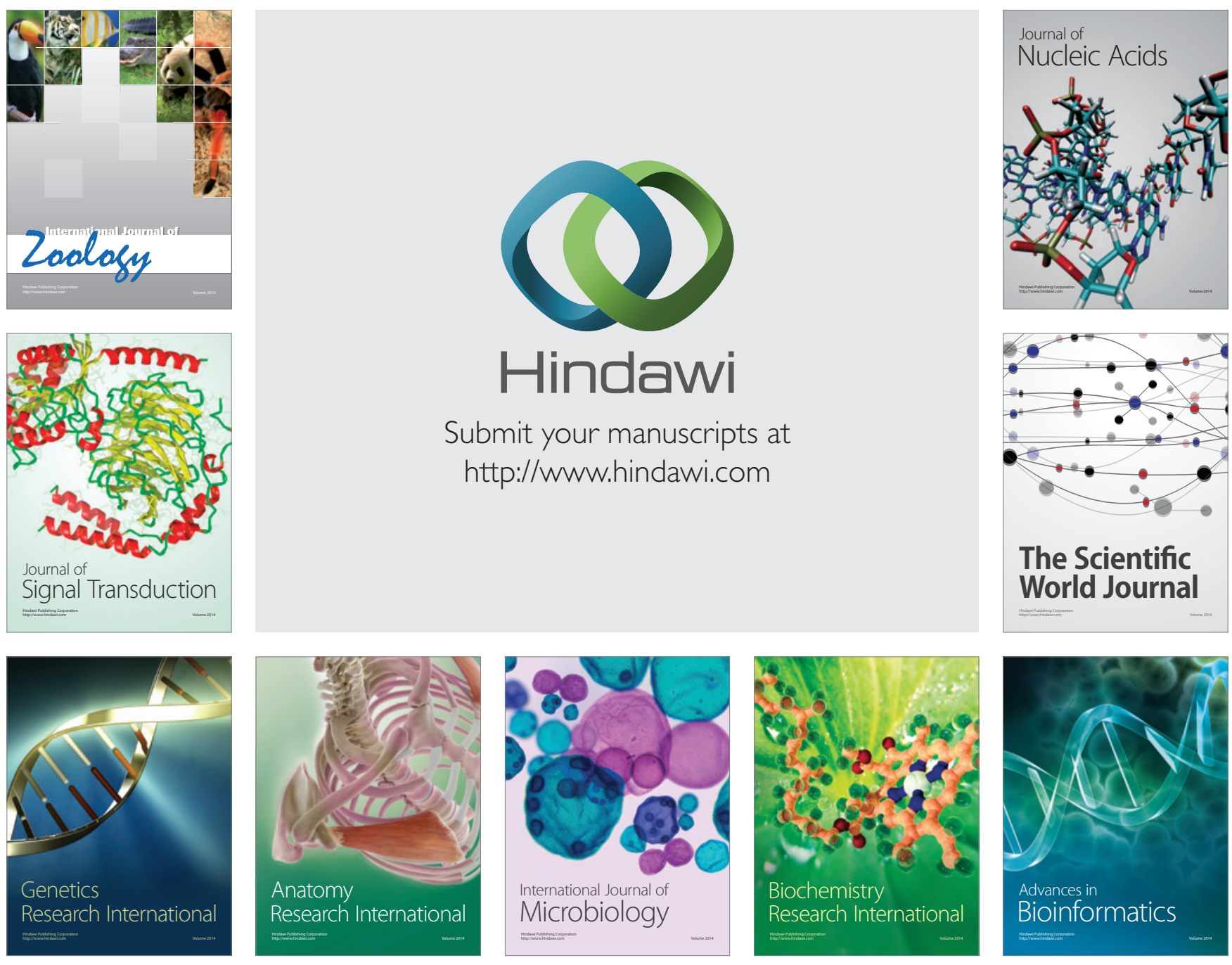

The Scientific World Journal
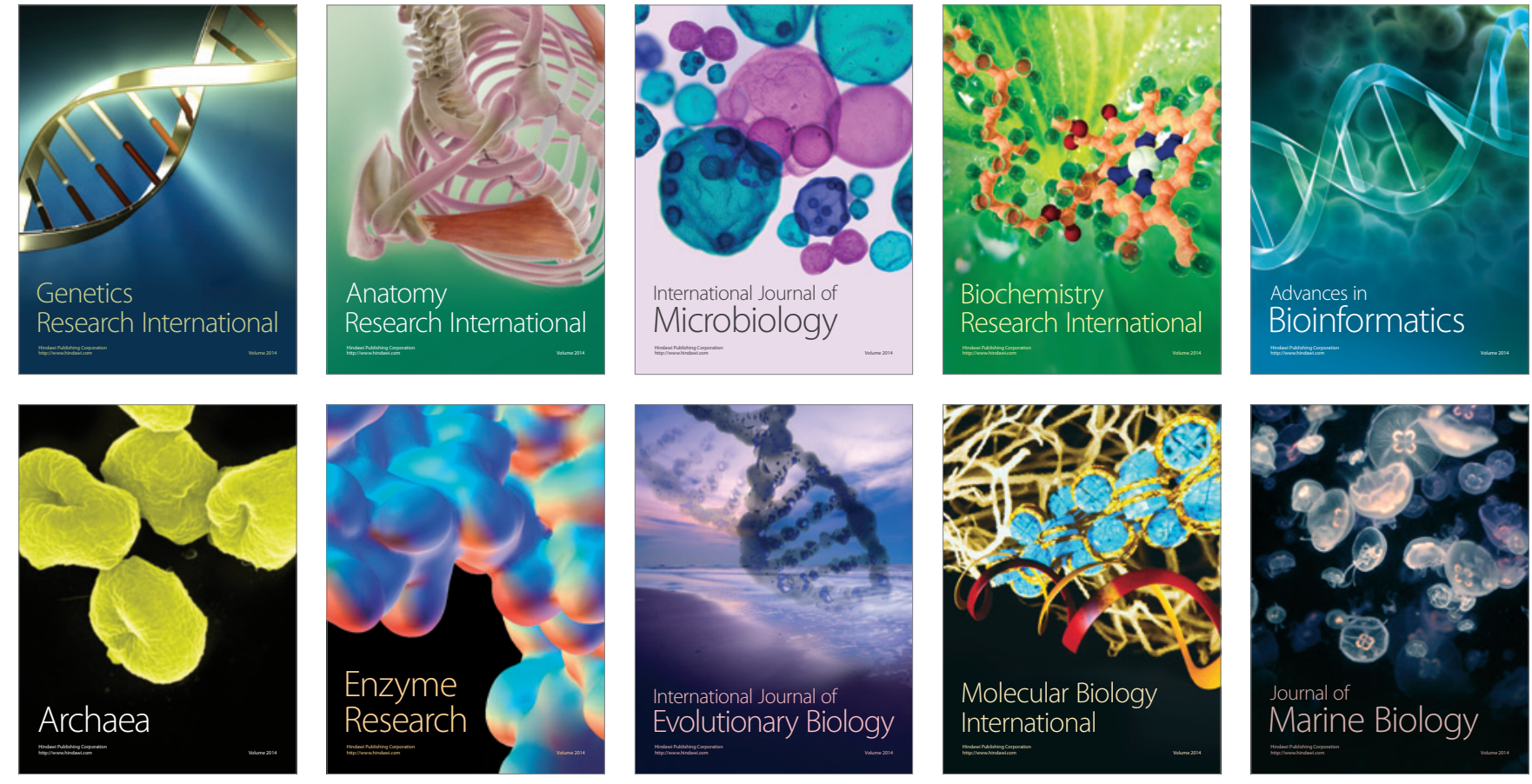